\title{
Educação física infantil e o jogo de faz de conta como estratégia pedagógica
}

\author{
Child physical education and the play of account as a pedagogical strategy
}

DOI: http://dx.doi.org/10.36453/2318-5104.2019.v17.n2.p203

\author{
Marcos Paulo Vaz de Campos Pereira ${ }^{1}$, José Ronivan Faria ${ }^{2}$, Adriano Correa Oliveira ${ }^{3}$, \\ Fabrício João Milan ${ }^{1}$, Virgínia Mara Próspero Cunha ${ }^{2}$, Gelcemar Oliveira Farias ${ }^{1}$ \\ ${ }^{1}$ Universidade do Estado de Santa Catarina (UDESC) \\ ${ }^{2}$ Universidade de Taubaté (Unitau) \\ ${ }^{3}$ Prefeitura Municipal de Caraguatatuba (SP)
}

\section{RESUMO}

Introdução: No contexto da educação infantil em Educação Física, práticas descontextualizadas e balizadas apenas pelo gesto motor limitam o desenvolvimento integral do educando. Objetivo: Diante deste cenário o objetivo é apresentar uma proposta pedagógica pautada no jogo de faz de conta, para o ensino da Educação Física na Educação infantil. Métodos: Trata-se de um ensaio teórico que propõe uma sistematização respaldada pelas dimensões dos conteúdos, utilizando o jogo de faz de conta como estratégia pedagógica e constituída por meio de uma rede complexa dos conteúdos. Resultados: A proposta pedagógica foi elaborada pelo agrupamento dos conteúdos: bola mão, bola pé, lutas, atividades rítmicas e expressivas. Conclusão: Esta proposta explora a criatividade do educando pela imprevisibilidade do jogo, permite a liberdade de expressão, e respeita seu conhecimento prévio, contribuindo para a sua formação integral. Não se trata de um modelo rígido, mas uma possível referência para o trabalho docente.

PALAVRAS-CHAVE: Educação Física; Jogos e Brinquedos; Escolas Maternais.

\section{ABSTRACT}

Background: In the context of physical education in early childhood education, practices decontextualized and marked only by the motor gesture limit the integral development of the student. Objective: In view of this scenario, the objective is to present a pedagogical proposal based on the play of account for the teaching of Physical Education in children's education. Methods: It is a theoretical essay that proposes a systematization supported by the dimensions of the contents, using the make-believe game as a pedagogical strategy and constituted through a complex network of contents. Results: The pedagogical proposal was elaborated by the grouping of contents: hand ball, foot ball, fights, rhythmic and expressive activities. Conclusion: This proposal explores the creativity of the learner by the unpredictability of the play, allows freedom of expression, and respects their prior knowledge, contributing to their integral formation. It is not a rigid model, but a possible reference for teaching work.

KEYWORDS: Physical Education; Play and Playthings; Schools Nursery. 


\section{INTRODUÇÃO}

No cenário da educação infantil em Educação Física a reflexão sobre a desvalorização do conhecimento que os educadores têm dos educandos versa essencialmente ao fato de parte deles desconsiderar a experiência das crianças, atuando como narradores e o educando como um ouvinte, um cumpridor de tarefas (SCAGLIA, 2007; KISHIMOTO, 2011; PEREIRA et al., 2018), ação que deve ser mediada na comunidade científica, no intuito de ampliar as dinâmicas pedagógicas desta etapa da educação básica. Tal criticidade é aceitável à medida que se oportuniza olhar para a prática pedagógica com mais atenção e cuidado, melhorando-a, ultrapassando o olhar mecanicista que por vezes perdura nos processos educacionais e que diminuem o pensar certo na estruturação dos sistemas de ensino (FREIRE, 2015). Consonante a este conceito, existe aparentemente um olhar distinto no que tange ao estímulo do imaginário infantil, especialmente quando as aulas de Educação Física se reportem a atividades em forma de circuito, jogos livres, com atividades descontextualizadas, favorecendo a limitação do aprendizado da criança em sua totalidade (FREIRE, 2002).

As propostas pedagógicas da Educação Física na educação infantil pautam-se apenas no movimento, sendo desenvolvidas através de gestos analíticos (FREIRE, 2002; CAVALARO; MULLER 2009). O Referencial Curricular para a educação infantil (BRASIL, 1998) apresenta como conteúdos a serem desenvolvidos, aqueles mediados por meio das expressões da linguagem corporal, a qual o educando deve ser estimulado por meio de imitações com jogos de faz de conta. Para tanto, o uso do jogo de faz de conta na educação infantil possibilita promover o desenvolvimento integral do educando, desde que o mesmo seja explorado a partir de práticas arrojadas, buscando a todo o momento desenvolver a autonomia e a interação entre educando e ambiente, igualmente desenvolvido (BRASIL, 2009).

Neste sentido, pode-se dizer que o jogo de faz de conta é uma atividade lúdica e abstrata que contribui para o processo de imaginação e criação da criança (VIGOTSKY, 1988; VIGOTSKY; COLE, 1991). Ademais, estas funções se desenvolvem por meio da interação dos alunos com o jogo e com a realidade que os cerca, e podendo ser utilizado como uma estratégia de ensino para se trabalhar com os conteúdos da cultura corporal de movimento humano (PEREIRA et al., 2018).

Destarte, acredita-se ser fundamental o uso de sistematizações que possam ir além de práticas reducionistas (FREIRE; SCAGLIA, 2003; SCAGLIA et al., 2014), utilizando estratégias como o jogo de faz de conta para o ensino da Educação Física nesta etapa tão importante para o desenvolvimento do educando (BRASIL, 2010). Além disso, articular o conhecimento adquirido e seu desenvolvimento integral, podendo ser realizadas a partir do jogo de faz de conta que apresenta uma gama de infinidades pedagógicas, desde que sistematizado de maneira eficaz e utilizado de maneira séria, proporcionará ao educando real importância em seu desenvolvimento (VIGOTSKY; COLE, 1991; FREIRE, 2002; BRASIL 2010; KISHIMOTO, 2011; FABIANI; SCAGLIA, 2018).

Portanto, embora que autores preocupados com a Educação Física na educação infantil tenham desenvolvido propostas para o ensino, o contexto educacional brasileiro carece de propostas pedagógicas que contribuam para uma formação do educando em sua totalidade. Assim o objetivo deste estudo é apresentar uma proposta pedagógica pautada no jogo de faz de conta para o ensino da Educação Física na educação infantil.

\section{MÉTODOS}

Este ensaio teórico apresenta uma proposta pautada no jogo de faz de conta como uma estratégia pedagógica para o ensino da Educação Física na educação infantil (FREIRE, 2002; KISHIMOTO, 2011; SAURA; MEIRELLES; ECKSCHMIDT, 2015), balizada pelas dimensões dos conteúdos (ZABALA, 1998; BARROSO; DARIDO, 2009), nomeadamente a dimensão conceitual, na qual se propõe as ações que o educando deve saber; a dimensão atitudinal, visando o que o educando deve ser em sua totalidade; e a dimensão procedimental, instigando o que educando deve saber fazer em consonância com as outras dimensões de conteúdos. Além destes fatores, a proposta foi constituída pela rede complexa de conteúdos dos jogos (ALBERT; BARABÁSI, 2002; PASSOS et al., 2011; LEONARDO; SCAGLIA; REVERDITO, 2009).

A organização desta proposta se fundamentou em autores que apresentam estudos sobre o jogo de faz de conta (VIGOTSKY; COLE, 1991; FREIRE, 2002; BRASIL 2010; KISHIMOTO, 2011; FABIANI; SCAGLIA, 2018), aqui sendo utilizado como um recurso pedagógico para ensinar os conteúdos. A rede complexa, que é o sistema desta proposta, foi elaborada com os seguintes conteúdos: bola mão, bola pé, atividades rítmicas e expressivas e lutas, que atuam em constante interação devido aos jogos. Cada conteúdo foi subdividido, formando uma rede de conteúdos, em que todos os jogos estão relacionados em níveis de dificuldade e níveis de estruturação. A justificativa pela escolha dos conteúdos se pauta na adaptação do referencial curricular proposto por Scaglia (2007). 


\section{RESULTADOS}

A concepção de educação infantil encontrava-se atrelada ao assistencialismo, no caso, um estabelecimento que consinta as necessidades básicas da criança, enquanto seus pais ou responsáveis atendem às demandas do mercado de trabalho, passando assim aos estabelecimentos de ensino funções que supram essa necessidade de assistência (CAVALARO; MULLER, 2009). Esta concepção de assistencialismo acaba por romper-se quando a sociedade começa a ter preocupações com este nível de ensino, consolidando políticas educacionais voltadas ao processo de ensino e de aprendizagem (SAYÃO, 1999; BRASIL, 1998; 2010).

Ainda assim, a educação infantil apresenta influência assistencialista, restringindo conteúdos e estratégias pedagógicas que enriqueçam o desenvolvimento do educando, se preocupando com suas necessidades básicas e limitando o que realmente ele necessita (SAYÃO, 1999; BRASIL, 2009; KISHIMOTO, 2011). Neste nível de ensino, a criança deve ser estimulada por meio da sua cultura, reconhecendo o mundo ao seu redor, expressado pelo brincar, criando e ressignificando o mundo cultural que o cerca (SAYÃO, 1999; CAVALARO; MULLER, 2009).

Ao refletir sobre o que deve ser estimulado na educação infantil, o currículo a ser desenvolvido deve-se pautar em diferentes linguagens para que o educando possa se expressar pela fala, por gestos, pela leitura, pela escrita e pela musicalidade (SACRISTÁN; GOMEZ, 2000; AYOUB, 2001; BRASIL, 2006). Este currículo deve prepará-lo para os demais níveis de ensino, mas colocando-o no centro do processo de ensino, tendo o educador que agir neste processo como um mediador que irá estruturar sua vivência na educação infantil (SAYÃO, 1999).

A Educação Física nesta fase ainda carece de documentos norteadores que favoreçam a pratica pedagógica do professor, sendo assim, as Diretrizes Curriculares Nacionais para a Educação Infantil elucidam o professor enquanto agente fundamental na criação e sistematização de propostas pedagógicas de qualidade que atentam as especificidades dos alunos nesta fase de constante desenvolvimento (BRASIL, 2010), mediante a isto, requer a ampliação de estudos que problematizem e que norteiem os professores de Educação Física. Por demais, os cursos de graduação devem primar por disciplinas que respaldem o futuro docente na educação infantil, como também formações continuadas podem atualizar os profissionais na busca de propostas e estratégias que os auxiliem na prática diária.

A Educação Física na educação infantil deve primar por objetivos que considerem o máximo de experiências lúdicas aos alunos, para tanto, respeitando suas características individuais (FILADELFO; FILADELFO, 2003; CARVALHO; SILVA JUNIOR, 2011). Consonante, a Base Nacional Comum Curricular apresenta objetivos de aprendizagem essenciais respaldados por brincadeiras e jogos em interação com os conteúdos a serem desenvolvidos. Tais objetivos são categorizados de acordo com a faixa etária do aluno, e para a Educação Física, é destaque o objetivo de utilizar o corpo pelo movimento intencionalmente mediante a criatividade e o controle para a interação com os demais colegas e com o ambiente (BRASIL, 2017), no caso desta proposta o ambiente de jogo.

Neste contexto, a Educação Física por meio dos jogos de faz de conta solicita que os educandos possam solucionar os problemas que emergem no jogo, atrelando-os aos desafios para a construção de aprendizagens dentro deste universo de criações (VIGOTSKY; COLE, 1991; FREIRE, 2002; SCAGLIA, 2007). Cabe ao educador compreender e respeitar cada educando, propiciando situações de desafios, criando dificuldades e problemas que permitam o seu desenvolvimento pela diversificação, a ampliação de experiências e o aprimoramento de novas formas de relação com seus colegas e com o ambiente em que se está inserido (SAYÃO, 1999).

O jogo, este fenômeno tão complexo e ao mesmo tempo tão encantador, remete as suas manifestações no contexto escolar, sendo exploradas pelos educandos através dos jogos de faz de conta em representações da realidade (FREIRE, 2002), do seu imaginário social, das suas emoções e de seus laços afetivos. Huizinga (1999) discorre sobre o jogo como uma atividade de caráter livre e lúdico que contém regras pré-estabelecidas ou criadas por seus participantes. Ao mesmo tempo, Freire e Scaglia (2003) apresentam o jogo como uma simulação lúdica da realidade concretizada nas ações das pessoas, no caso dos educandos quando brincam, e sendo compreendido quando é jogado plenamente (VIGOTSKY; COLE, 1991; KISHIMOTO, 1999; FREIRE, 2002; ZIMMERMANN; SAURA, 2014).

Na educação infantil o jogo é caracterizado pelas manifestações do educando em representar algo, como um personagem ou com um símbolo, com isso é por meio do jogo que a criança consegue construir a habilidade de imaginar (VIGOTSKY; COLE, 1991; FREIRE, 2002). É no jogo simbólico que o educando descobre e compreende o seu "eu" por meio das explorações constantes durante suas atividades, utilizando os movimentos corporais nos jogos de imitação para criar e ressignificar o seu contexto de aprendizagem. (SILVA; RUBIO, 2014).

Com relação da área da Educação Física, o jogo pode ser utilizado como um conteúdo e como uma estratégia de ensino, devendo ser utilizado nas aulas com um equilíbrio entre a sua função pedagógica e a sua lúdica (KISHIMOTO, 2011; PEREIRA et al., 2018). Deste modo, caberá ao educador compreender como irá utilizar o jogo com as funções pedagógicas, visando ensinar algum conteúdo, e a função lúdica, visando o prazer e a imersão do aluno no ambiente de jogo.

Ao ser utilizado, este jogo é sistematizado a partir de uma representação simbólica do educando, que de acordo 
com Vigotsky (1988) torna-se necessária para uma reflexão sobre o jogo de faz de conta como possibilidade de ensino, já que o mesmo possibilita despertar a imaginação da criança trabalhando com significados culturais do grupo social ao qual a criança pertence (FREIRE, 2002; SCAGLIA, 2007; KISHIMOTO, 2011). Esta representação simbólica deve se pautar em um ambiente em que o ensino e a aprendizagem possam associar-se na dimensão complexa do jogo, e desenvolver os objetivos propostos para a aula (SCAGLIA, 2007; KISHIMOTO, 2011). Este mundo de imaginação do fenômeno complexo do jogo pode ser representado pelo seu ambiente, uma vez que se torna necessário percebê-lo para além duas suas aparências primárias, seus desdobramentos culturais, bem como sua facilitação de aprendizagem (SCAGLIA, 2003):

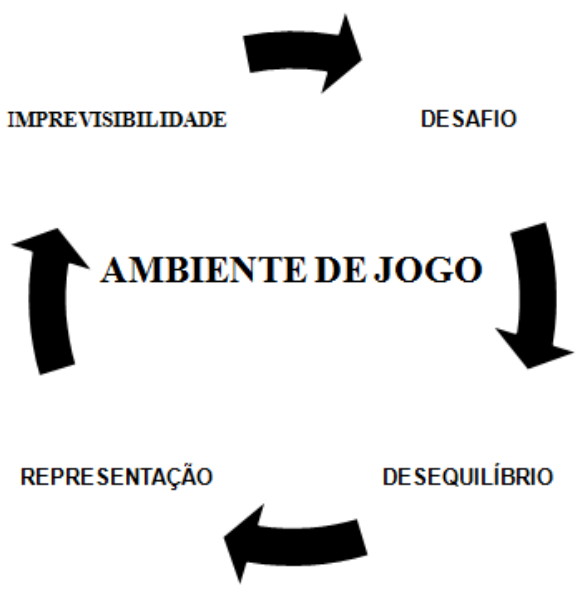

Figura 1. Ambiente de Jogo.

Fonte: os autores 2019.

O ambiente de jogo (Figura 1) tem predomínio de desafios, em que o educando terá que procurar recursos para resolvê-los. Há, por exemplo, a representação sempre presente, em imitar personagens e símbolos transportando o educando para mundos imaginários a partir de histórias. A imprevisibilidade encontra-se presente a todo o momento neste tipo de cenário, pois as tomadas de decisões e as mudanças contínuas no ambiente do jogo não são determinadas previamente. O desequilíbrio é um excelente exemplo desta perspectiva, visto que acaba tirando o educando do seu equilíbrio natural para um mundo onde terá de interagir e ser criativo para solucionar as situações problemas ao qual estará submetido no jogo (FREIRE, 2002; SCAGLIA, 2007; SCAGLIA et al., 2013). Este ambiente que irá proporcionar aproximações entre o contexto e as interações do educando com o jogo estabelecido, conduz um papel de responsabilidade também ao educador, que poderá aumentar a complexidade do jogo conforme o educando consiga resolver os problemas encontrados neste ambiente (FREIRE, 2002).

Nesta dinâmica, o jogo de faz de conta apresenta inúmeros fins pedagógicos, que vão desde a interação entre seus praticantes, o conhecimento prévio do educando que é levado em consideração, as habilidades motoras e cognitivas que são desenvolvidas pelas situações problemas que surgem durante o jogo, a liberdade de escolha nas respostas, até o estimulo a criatividade do educando (FREIRE, 2002; SCAGLIA, 2007; KISHIMOTO, 2011; ZIMMERMANN; SAURA, 2014). Estes benefícios auxiliam no desenvolvimento da criança, embora, quando estiverem relacionados aos jogos de faz de conta sistematizados, deve-se observar se estes jogos atendem aos conteúdos que pretende-se desenvolver, como também buscar respaldo nas dimensões dos conteúdos, nomeadamente a atitudinal, a conceitual e a procedimental. A sistematização dos conteúdos utilizando o jogo de faz de conta como estratégia pedagógica deve se respaldar na visão de compreensão de mundo do educando, seus pensamentos e suas escolhas (BRASIL, 1998; FREIRE, 2002).

Uma sistematização deve se pautar na seleção de conteúdos que possam contribuir de maneira significativa na formação do educando (SACRISTÁN; GOMEZ, 2000). Em conformidade, esta organização encontra-se pautada no jogo de faz de conta como uma estratégia de ensino para se trabalhar os conteúdos, sendo esta sistematizada no horizonte do agrupamento dos seguintes conteúdos: bola mão, bola pé, lutas, atividades rítmicas e expressivas.

O agrupamento dos conteúdos de atividades rítmicas e expressivas oferece a maior gama de possibilidades em relação às habilidades que podem ser transferidas por meio dos jogos. Estas habilidades isoladas, como correr ou combinadas como correr e saltar são contempladas neste conteúdo de maneira menos e mais complexa, dependendo do jogo a ser desenvolvido. Nesta perspectiva, o educador tem uma variedade de possibilidades para criar jogos que sirvam 
de base para desenvolver estas habilidades ou mesmo que interajam com os outros conteúdos e outras habilidades desenvolvidas, como: rolar, correr, saltar, dançar, manipular, lançar e chutar que podem surgir conforme a necessidade do jogo.

Quanto aos agrupamentos dos conteúdos, o conteúdo de bola mão será um agrupamento de jogos de faz de conta em que o educando deve utilizar prioritariamente os membros superiores. Salienta-se que, os jogos que o educador irá elaborar devem contemplar vivências que estimulem o educando a experimentar vários tamanhos, cores, formatos, pesos e texturas de bolas. Da mesma maneira em relação às diversas habilidades, como arremessos, manipulações, voleios, agarres, dentre outras habilidades específicas para este agrupamento de conteúdos.

O conteúdo de bola pé será um agrupamento de jogos de faz de conta em que o educando deve utilizar-se prioritariamente os membros inferiores, contribuindo no desenvolvimento de habilidades como o chute e a manipulação com os pés. Este conteúdo possui uma grande semelhança com o conteúdo anterior, possibilitando a transferência de conhecimento e habilidades para o educando. Este cenário possibilita ao educador conseguir relacionar os conteúdos, podendo criar novas variações aos jogos já propostos sem que haja uma fragmentação de um conteúdo para o outro.

Sobre o conteúdo de lutas, este será um agrupamento realizado por vários jogos para que o educando possa ter uma vivência dos princípios das lutas, como por exemplo, jogos que o façam utilizar de rolamentos, agarre, contato, toque e manipulação de implementos. Assim como os demais conteúdos, continua-se com a transferência de habilidades de um conteúdo para outro, valorizando-se todos os conteúdos e jogos semelhantes em diferentes graus de complexidade.

Estes conteúdos foram agrupados ao que denomina-se unidades complexas, em que formam uma rede complexa de conteúdos e um sistema organizacional a qual prima pela diversidade, dificuldade e estruturação dos jogos de faz de conta a serem desenvolvidos (SCAGLIA, 2003; SCAGLIA 2007; LEONARDO; SCAGLIA; REVERDITO, 2009). Deste modo, esta sistematização é chamada de rede complexa de jogos, advinda de teorias interdisciplinares que abrangem várias áreas do conhecimento com o intuito de potencializar a interação entre os conteúdos a partir de uma visão sistêmica e complexa (SCAGLIA, 2007; PASSOS et al., 2011) e ao mesmo tempo transpassar as barreiras na maneira como se pensa o conhecimento, relacionando-o com o todo (PETRAGLIA, 2002).

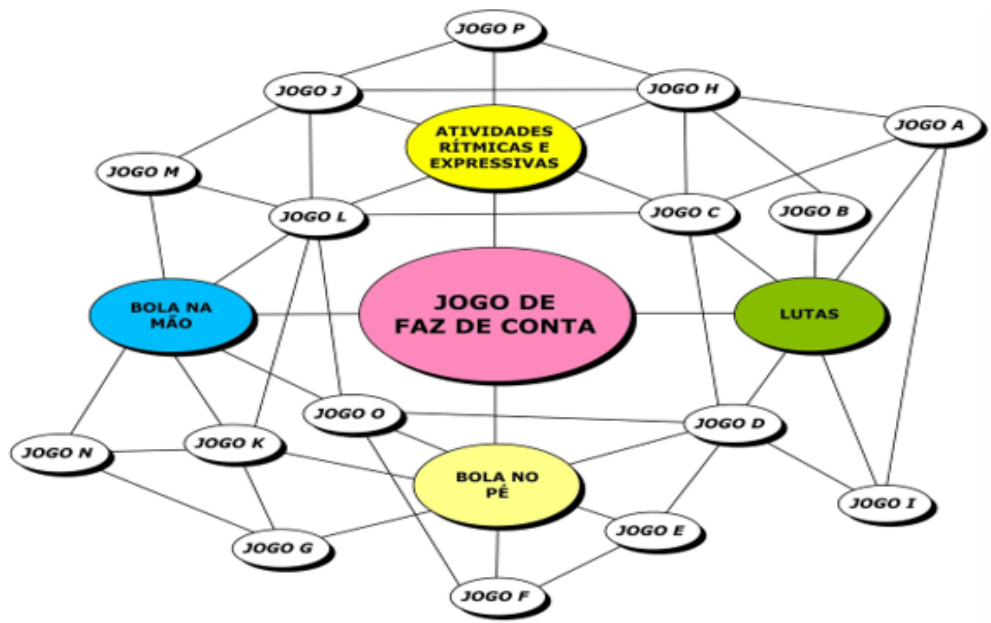

Figura 2. Rede complexa de conteúdos.

Fonte: os autores 2019.

A rede complexa (Figura 2) é composta pelos jogos que formam os vértices menores com níveis de complexidade e pelos conteúdos que formam os vértices maiores, as conexões entre os jogos e os conteúdos que estão representados por arestas as quais se relacionam aos níveis de complexidade dos jogos e seus conteúdos, sendo que estes níveis de complexidade se estabelecem conforme o número de conexões na rede (ALBERT; BARABÁSI, 2002; PASSOS et al., 2011; LEONARDO; SCAGLIA; REVERDITO, 2009). Estas relações entre os conteúdos irão potencializar o aprendizado do educando, pois o mesmo irá transferir o que aprendeu em um conteúdo para outro, compreendendo-se a lógica do jogo (PEREIRA et al., 2016). Já o educador terá para si um modelo que o irá auxiliar na elaboração de jogos que trabalhem os conteúdos propostos, de modo à alcançar seus objetivos estabelecidos, bem como desenvolver as habilidades motoras e cognitivas do educando. 
Tão importante quanto à figura do educador e do educando neste processo, é a figura da escola, local social em que estas transformações ocorrem. As relações dos conhecimentos construídos a partir do jogo são como uma unidade indissociável da vida, relacionadas explicitamente ao meio, pois, tanto educadores como a escola, não podem perder de vista que a construção individual da identidade (no caso os educandos) estimula a construção da identidade da escola, ambos sujeitos de um processo de conhecimento orientado pelo jogo e sua complexidade (PETRAGLIA, 2002).

As características sistêmicas do jogo também favorecem as conexões entre as três dimensões dos conteúdos, a qual irão balizar os jogos de faz de conta durante as aulas, em rodas de conversa com questões referentes ao jogo, desde a sua estruturação, as regras e as decisões do educando para resolver os problemas que emergem nos jogos trabalhados. Ademais, as dimensões atitudinais e conceituais emergem das situações de jogo (procedimental), que as quais são contempladas mediante regras, histórias, questionamentos e criação de outros jogos tanto pelo professor, quanto pelos alunos.

Ainda com relação a dimensão dos conteúdos, especificando a utilização de cada um dos três, o conteúdo conceitual irá se referir a fatos e onde as aulas devem ser abordadas a partir de histórias e fábulas, explorando o universo imaginário do educando. O conteúdo atitudinal irá se referir ao respeito, a discussão, a compreensão de normas e condutas do jogo a partir de questionamentos durante toda a aula. E o conteúdo procedimental abordará os jogos propostos em consonância com as outras dimensões de conteúdos, onde o educador irá mediar às situações problemas, buscando descentralizar a aula de si, gerando um ambiente de aprendizagem centralizado no educando (ZABALA, 1998; BARROSO, DARIDO, 2009).

É importante mencionar, que esta rede é um modelo abstrato, no qual foram selecionados conteúdos mediante adaptação da proposta curricular de Scaglia (2007), sendo balizada pelas dimensões dos conteúdos e respaldada pelo jogo de faz de conta, uma estratégia pedagógica ao alcance do docente, que poderá organizar e modificar suas aulas a medida que os alunos irão compreendendo a diversidade de jogos, e transferindo as habilidades de um jogo para outro, de um conteúdo para outro. Além disso, com as dimensões dos conteúdos interligadas, os alunos irão aprender regras fundamentais para os jogos, como também conceitos primordiais que terão significados para os alunos dentro e fora do ambiente de jogo.

\section{CONSIDERAÇÕES FINAIS}

Diante do atual cenário da Educação Física na educação infantil, requer a necessidade de propostas que explorem o universo imaginário do educando. Assim, esta proposta pedagógica que utiliza o jogo de faz de conta como uma estratégia de ensino, sendo balizado pelas dimensões dos conteúdos e sistematizado pela rede complexa, consegue nortear a prática docente corroborando para que o educador consiga elaborar aulas diversificadas que contemplem os conteúdos da Educação Física nesta tão importante fase do desenvolvimento de seus educandos. Além disso, oportuniza também relacionar os conteúdos por seus níveis de complexidade à medida que o educando resolva as situações emergentes do jogo proposto. Portanto, essa proposta metodológica explora a criatividade e autonomia do educando pela imprevisibilidade do jogo, permitindo a liberdade de expressão, respeitando o conhecimento prévio do educando e contribuindo para a sua formação integral. Esta proposta pedagógica não apresenta um modelo rígido, pois a rede complexa não estabelece uma sequência de hierarquização obrigatória de conteúdos, assim o educador poderá adequar os jogos de faz de conta para a realidade onde se encontra.

Esta proposta limita-se apresentar o jogo de faz de conta como estratégia de ensino por meio de uma rede complexa, nesse sentido, recomenda-se para novos estudos acerca da temática explorar outros conteúdos propostos para a educação infantil, que estão ausentes neste ensaio por respaldo da adaptação da proposta curricular de Scaglia (2007). Como também, estender esta proposta para os demais níveis de ensino (fundamental e médio), e aprofundar a discussão de propostas pedagógicas na graduação e em formações continuadas.

\section{REFERÊNCIAS}

ALBERT, R.; BARABÁSI, A. Statistical mechanics of complex networks. Reviews of Modern Physics, Washington, v. 74, n. 1, p. 47-97, 2002.

AYOUB, E. Reflexões sobre a educação física na educação infantil. Revista Paulista de Educação Física, São Paulo, v. 1, Supl.4, p. 53-60, 2001.

BARROSO, A. L. R., DARIDO, S. C., Pedagogia do Esporte e as dimensões dos conteúdos: conceitual, procedimental e atitudinal. Revista da Educação Física, Maringá, v. 20, n. 2, p. 281-9, 2009. 
BRASIL. Ministério da Educação. Diretrizes curriculares nacionais para a educação infantil. Secretaria de Educação Básica. Secretaria de Educação Básica. Brasília: MEC, SEB, 2010. Disponível em: <http:// portal.mec.gov.br/docman/julho-2013-pdf/13677-diretrizes-educacao-basica-2013-pdf/file>. Acessado em: 21 de janeiro de 2019.

BRASIL. Ministério da Educação. Indicadores da Qualidade na Educação Infantil. Secretaria da Educação Básica. Brasília: MEC/SEB, 2009.Disponível em: <http://portal.mec.gov.br/dmdocuments/ indic qualit educ infantil.pdf>. Acessado em: 21 de janeiro de 2019.

BRASIL. Ministério da educação. Base Nacional Comum Curricular: Educação é a base. Brasília: MEC, 2017. Disponível em: <http://basenacionalcomum.mec.gov.br/>. Acessado em: 21 de janeiro de 2019.

BRASIL. Ministério da Educação. Parâmetros nacionais de qualidade para a educação infantil. Secretaria de Educação Básica. Volume 1. Brasília, DF, 2006. Disponível em: <http://portal.mec.gov. br/seb/arquivos/pdf/Educinf/eduinfparqualvol1.pdf>. Acessado em: 21 de janeiro de 2019.

BRASIL. Ministério da Educação e do Desporto. Referencial curricular nacional para a educação infantil. Secretaria de Educação Fundamental. Brasília: MEC/SEF, 1998. Disponível em: <http:// portal.mec.gov.br/seb/arquivos/pdf/rcnei vol1.pdf>. Acessado em: 21 de janeiro de 2019.

CARVALHO, A. G. S.; SILVA JÚNIOR, A. P. Educação física na educação infantil no município de Marechal Cândido Rondon - PR: um estudo de caso. Caderno de Educação Física, Marechal Cândido Rondon, v. 10, n. 18, p. 47-57, 2011.

CAVALARO, A. G.; MULLER, V. R. Educação física na educação infantil: uma realidade almejada. Educar, Curitiba: Editora UFPR, 2009.

FABIANI, D. J.; SCAGLIA, A. J. O inventário da cultura lúdica: os espaços, os materiais e os jogos desenvolvidos pelas crianças no horário livre. Ludicamente, Buenos Aires, v. 14, n. 7, p. 1-22, 2018.

FILADELFO, E. A. P.; FILADELFO, J. R. Análise das teorias dos estágios aplicadas aos estudos do desenvolvimento infantil. Caderno de Educação Física, Marechal Cândido Rondon, v. 5, n. 10, p. $189-94,2003$

FREIRE, J. B. O Jogo entre o riso e o choro. São Paulo: Autores Associados, 2002.

FREIRE, J. B.; SCAGLIA, A. J. Educação como prática corporal. São Paulo: Scipione, 2003.

FREIRE, P. Pedagogia da Autonomia. Rio de Janeiro: Paz e Terra, 2015.

HUIZINGA, J. Homo ludens: o jogo como elemento da cultura. São Paulo: Perspectiva, 1999.

KISHIMOTO, T. M. O brincar e suas teorias. São Paulo: Cengage Learning, 2011.

LEONARDO, L.; SCAGLIA, A. J.; REVERDITO, R. S. O Ensino dos Esportes Coletivos: Metodologia pautada na Família dos Jogos. Motriz, Rio Claro, v. 15, n. 2, p. 236-46, 2009.

PASSOS, P.; DAVIDS, K.; ARAUJO, D.; PAZ, N.; MINGUÉNS, J.; MENDES, J. Networks as a novel tool for studying team ball sports as complex social systems. Journal of Science and Medicine in Sport, Oxford, v. 14, n. 2, p. 170-6, 2011.

PEREIRA, M. P. V. C.; CIRINO, C.; MILAN, F. J.; RESENDE, R. Reflexões Sistêmicas do Jogo: Contribuições para a Educação Física. Journal of Sport Pedagogy and Research, Maia, v. 4, n. 3, p. 60-4, 2018.

PEREIRA, M. P. V. C.; FARIAS, G. O.; CIRINO, C.; SCAGLIA, A. J. O jogo como estratégia pedagógica para o ensino da educação física escolar no 5o ano do ensino fundamental I. Corpoconsciência, Cuiabá, v. 20, n. 3, p. 1-8, 2016.

PETRAGLIA, I. C. Edgar Morin: a educação e a complexidade do ser e do saber. Petrópolis: Vozes, 2002.

SACRISTÁN, J. G.; GOMEZ, A. I. P. Compreender e transformar o ensino. Porto Alegre: Artes Médicas, 2000.

SAURA, S. C.; MEIRELLES, R.; ECKSCHMIDT, S. Educação Física Escolar: sentir, pensar e agir na Educação Infantil - considerações para um possível caminho do brincar espontâneo. Revista Brasileira de Educação Física e Esporte, São Paulo, v. 29, Supl. 29, p. 29-27, 2015.

SAYÃO, D. T. Educação física na educação infantil: riscos, conflitos e controvérsias. Motrivivência, Florianópolis, v. 6, n. 13, p. 221-40, 1999. 
SCAGLIA, A. J. O futebol e os jogos/brincadeiras de bola com os pés: todos semelhantes, todos diferentes. 2003. 164 f. Tese (Doutorado em Educação Física) - Universidade Estadual de Campinas, Campinas, 2003

SCAGLIA, A. J.; REVERDITO, R. S.; GALATTI, L. R. A contribuição da pedagogia do esporte ao ensino do esporte na escola: tensões e reflexões metodológicas. In: MARINHO, A.; NASCIMENTO, J. V. do; OLIVEIRA, A. A. B. (Orgs.). Legados do esporte brasileiro. Florianópolis: UDESC, 2014.

SCAGLIA, A. J.; REVERDITO, R. S.; LEONARDO, L.; LIZANA, C. J. R. O ensino dos jogos esportivos coletivos: as competências essenciais e a lógica do jogo em meio ao processo organizacional sistêmico. Movimento, Porto Alegre, v. 19, n. 4, p. 227-49, 2013.

SCAGLIA. Referencial Curricular da Educação básica das Escolas Públicas Municipais de Franca. Franca (SP), 2007. Disponível em: <https://www.franca.sp.gov.br/uncategorised/referencialcurricular-da-educacao-basica-das-escolas-publicas-do-municipio-de-franca>. Acessado em: 07 de outubro de 2017.

SILVA, R. A. S.; RUBIO, J. A. S. A utilização do jogo simbólico no processo de aprendizagem na educação infantil. Revista Eletrônica Saberes da Educação, São Roque. v. 5, n. 1, p. 1-15, 2014.

VIGOTSKY, L. S. Aprendizagem e desenvolvimento intelectual na idade escolar: linguagem, desenvolvimento e aprendizagem. São Paulo: Ícone, 1988.

VIGOTSKY, L. S.; COLE, M. A formação social da mente: o desenvolvimento dos processos psicológicos superiores. São Paulo: Martins Fontes, 1991.

ZABALA, A. A prática educativa: como ensinar. Porto Alegre: Artmed, 1998.

ZIMMERMANN, A. C.; SAURA, S. C. Jogos tradicionais. São Paulo: Laços, 2014.

Autor correspondente: Marcos Paulo Vaz de Campos Pereira

E-mail: marcosp.pereira46@gmail.com

Recebido: 08 de fevereiro de 2019.

Aceito: 09 de outubro de 2019. 